\title{
Optimization of Injection Pressure and Injection Timing on Fuel Sprays, Engine Performances and Emissions on a Developed DI 20C Biodiesel Engine Prototype
}

\author{
Bambang Sudarmanta $^{1 *}$, Alham A.K. Mahanggi ${ }^{1}$, Dori Yuvenda ${ }^{2}$, Hary Soebagyo $^{3}$ \\ ${ }^{1}$ Department of Mechanical Engineering, Institut Teknologi Sepuluh Nopember, Surabaya 60111, Indonesia \\ ${ }^{2}$ Department of Automotive Engineering, Universitas Negeri Padang, Padang 25171, Indonesia \\ ${ }^{3}$ Department of Mechanical Engineering, Universitas Pancasila, Jakarta 12630, Indonesia
}

Corresponding Author Email: sudarmanta@me.its.ac.id

https://doi.org/10.18280/ijht.380408

Received: 17 March 2020

Accepted: 24 August 2020

\section{Keywords:}

biodiesel, performances, emissions, injection

pressure, injection timing

\begin{abstract}
Biodiesel, as a renewable fuel that has the potential to replace diesel fossil fuels. With properties in the form of viscosity, density, and surface tension, which are higher than diesel fossil fuel, biodiesel produces poor spray characteristics, and also the high cetane number and oxygen content so that the ignition delay is shorter causes the start of combustion will shift more forward, therefore need to improve injection parameters including injection pressure and timing. The aim of this research is to get the optimal injection parameter optimization so as to improve engine performances and emissions. The method used is to increase the fuel injection pressure from 200 to $230 \mathrm{~kg} / \mathrm{cm}^{2}$ and the injection timings were retarded from $22^{\circ}$ to $16^{\circ} \mathrm{BTDC}$. The results show that increasing injection pressure can improve spray characteristics as indicated by shorter penetration and smaller spray diameter of $30 \%$ and $9.8 \%$, respectively and increase in spray spread angle of $21.9 \%$. Then the optimization of engine performances and emissions, obtained at an injection pressure of $230 \mathrm{~kg} / \mathrm{cm}^{2}$ and injection timing of $16^{\circ}$ BTDC with an increase of power and thermal efficiency of $3.9 \%$ and $13.9 \%$, respectively and reduction in smoke emissions of $45.2 \%$ at high load.
\end{abstract}

\section{INTRODUCTION}

Indonesia still relies on the use of fossil fuels. Fossil fuels are non-sustainable energy sources, which are commonly used in industrial and transportation fields. For example, diesel, dexlite, and pertadex fuels were the result of the distillation of fractions from petroleum (fossil fuels), in which the availability is limited. The use of fossil fuels also has a negative impact on the environmentally. Exhaust emissions from the combustion of fuel are one of the main causes of the greenhouse effect (such as $\mathrm{CO}, \mathrm{CO}_{2}, \mathrm{HC}$, etc.). With the adverse effects of the depletion of fossil fuels, alternative fuels are needed to reduce dependence on fossil fuels.

Biodiesel is a fuel that is very potential to be used as a substitute for diesel fossil fuels and research has been conducted related to biodiesel fuels [1]. Many studies have implemented the use of biodiesel fuels in diesel engines [2-4]. This is because the raw materials derived from vegetable oils can be renewed, can be produced periodically and easily obtained. However, with properties in the form viscosity, density, and surface tension, which are higher value than diesel fossil fuels, biodiesel produces poor spray characteristics. In addition, with higher value of cetane numbers, the ignition delay is shorter, and the presence of oxygen in biodiesel [5] causes the premixed combustion process to be faster [6]. Nguyen et al. [7] investigated spray characteristics, performance, and emissions on diesel engine using biodiesel fuel. They explained that the penetration of biodiesel fuel is longer than the diesel fossil fuel. In addition, an increase in the ratio of biodiesel blends leads to an increase in spray penetration caused by higher viscosity and spray droplet size. As a result, larger spray droplets and higher momentum. The viscosity and density of biodiesel fuels are higher so that there are longer droplets around the injector and greater momentum than diesel fuel. As a result, the spray leads to more combustion chamber walls and smaller spray angles than diesel fossil fuels.

Some researchers carried out the experimental study on the effect of injection pressure variations using biodiesel fuel. Mahanggi et al. [8] reported that an increase in injection pressure could improve these sprayed characteristics, performance, and exhaust gas emissions. Other properties, specifically cetane number, where the higher the cetane number can also result in a shorter ignition delay. A shorter ignition delay can reduce the time of mixing of fuel-air, and the starting point of flame formation is advancing, but it is certain that this time produces a more efficient performance in mixing fuel and air because the temperature and incoming air pressure become higher so that the fuel is ready to burn. Therefore, treatment is needed, which is to adjust of injection timing to get a perfect fuel atomization, combustion process so produces a performance on engines that are close to or equal to using diesel fossil fuels.

Sita and Sudarmanta [9] conducted a study of the effect of injection pressure on performance on diesel dual fuel engine. Variations are made by changing the thickness of the shim or adjusting the injector washer according to the variation, namely $190,210,230$, and $250 \mathrm{~kg} / \mathrm{cm}^{2}$ with a constant engine speed of $2000 \mathrm{rpm}$ and electrical loading from 200 watt to 2000 watt with intervals of 200 watt, at diesel dual fuel system 
biodiesel-syngas fuels. The best performance results obtained at a pressure of $250 \mathrm{~kg} / \mathrm{cm}^{2}$ with an increase in the percentage of thermal efficiency of $40.77 \%$ and spray angle $(\alpha)$ of $29.41 \%$, and a decrease in the percentage of SFC and spray length $(L)$ of $13.24 \%$ and $19.23 \%$, respectively.

Mutyalu et al. [10] investigated the effect of fuel injection pressure on the performance and emissions characteristics of a diesel engine with shea olein biodiesel fuel. The experiment was carried out on stationary water-cooled naturally aspirated single-cylinder four-stroke and direct injection diesel engine at a constant rated speed of $1500 \mathrm{rpm}$ and load at $2.79 \mathrm{~kW}$. The test was conducted at different injection pressures (190, 200, 210, 220, 230 bar). The best performance and emissions are produced at an injection pressure of 210 bar. Where the results of chart trends such as SFC have decreased at an injection pressure of 210 bar. While at higher injection pressures, SFC has increased because of higher momentum of fuel got impinges on cylinder walls leads to wastage of fuel and improver combustion. $\mathrm{HC}$ and $\mathrm{CO}$ emissions also decrease at an injection pressure of 210 bar.

Some researchers carried out the experimental study on the effect of injection timing variations using biodiesel fuels. Mendonca et al. [11] conducted a study on the influence of injection timing on performance and emission characteristics of simarouba biodiesel engine. The experimental aims at determining appropriate proportions of biodiesel and diesel fossil fuel for which higher efficiency is obtainable. Standard injection timing is $20.5^{\circ} \mathrm{BTDC}$, and then variations are carried out by advancing and retarding injection timing to be $25.5^{\circ}$ and $15.1^{\circ}$ BTDC. For B20 fuel, the best performance results obtained at the timing of retarding $15.1^{\circ}$ BTDC with improvement in brake thermal efficiency and brake specific fuel consumption. While advancing injection timing $25.5^{\circ}$ BTDC, resulting in reduced performance compared to the standard injection timing.

Hirkude et al. [12] where this study aims to determine the effects of compression ratio and injection parameters such as injection pressure and injection timing of performance and emissions in a diesel engine. This research was conducted using different compression ratios, namely 16, 17, 18, and 19, and variations in injection parameters such as injection timing, namely $24^{\circ}, 27^{\circ}$, and $30^{\circ} \mathrm{BTDC}$, and an injection pressure of 200, 225, 250 bar. The best performance results were obtained at the compression ratio of 18 and injection pressure of 250 bar, and standard injection timing $27^{\circ}$ BTDC. If advancing injection timing, the percentage increase of $2.01 \%$, while the retarding injection timing increase of $6 \%$. At injection pressure of $250 \mathrm{bar}$, the advancing of injection timing from $27^{\circ}$ to $30^{\circ}$ BTDC reduced smoke opacity by $3.03 \%$. While retarding injection timing by $27^{\circ}$ to $24^{\circ}$ BTDC increased smoke opacity by $3.34 \%$.

Based on previous research that the use of biodiesel fuel with its properties, requires setting injection pressure and injection timing. Thus, this study aims to improve fuel sprays, engine performances and emissions through optimization of injection pressure and injection timing on a developed DI 20C biodiesel engine prototype with crude palm oil (CPO) biodiesel fuel at low, medium, and high engine loads.

The design of a developed DI 20C biodiesel engine prototype is accorded to the characteristics of biodiesel fuels and operational condition parameters including injection pressure, injection timing, multi stage injection, and forced air combustion. This research has been carried out optimization of injection pressure and injection timing on a developed DI
20C biodiesel engine using CPO biodiesel fuel. The results of this research are fuel sprays, engine performances, emissions and engine operating temperatures can be improved.

\section{EXPERIMENTAL SETUP}

\subsection{Fuel properties}

The biodiesel used in this test was biodiesel (B100) from crude palm oil (CPO) obtained from PT. Wilmar Nabati Indonesia, where biodiesel in Indonesia uses more raw materials from palm oil because it is easily obtained [13]. But when compared to diesel fossil fuels, the properties of biodiesel fuels have a higher value of viscosity, density, surface tension, and cetane number but low at the heating value. Table 1 shows differences in the properties of diesel fossil and CPO biodiesel fuels.

Table 1. The comparison of fuel properties

\begin{tabular}{ccc}
\hline Properties & Diesel fossil & Biodiesel \\
\hline Lower caloric value $[\mathrm{kJ} / \mathrm{kg}]$ & 46218.09 & 42542.54 \\
Density at $15^{\circ} \mathrm{C}\left[\mathrm{kg} / \mathrm{m}^{3}\right]$ & 857 & 875 \\
Density at $40^{\circ} \mathrm{C}\left[\mathrm{kg} / \mathrm{m}^{3}\right]$ & 844 & 857 \\
Kinematics viscosity at $40^{\circ} \mathrm{C}$ & 4.2 & 4.5 \\
{$\left[\mathrm{~mm}^{2} / \mathrm{s}\right]$} & 66 & 68 \\
Surface tension [dyne $/ \mathrm{cm}]$ & 53 & 58 \\
Cetane number & & \\
\hline
\end{tabular}

\subsection{Engine test}

The engine used is designed specifically using biodiesel fuels. The specifications of a developed DI 20C biodiesel engine prototype is shown in Table 2.

Table 2. The specifications of engine test

\begin{tabular}{cc}
\hline Engine specifications & Description \\
\hline Merk & diamond \\
Model & DI 20C \\
Engine type & four-stroke, horizontal, water \\
Fuel injection system & cooled \\
Start of injection $\left[{ }^{\circ}\right.$ BTDC] & direct injection \\
Compression ratio & 20 \\
Bore [mm] & $16: 1$ \\
Stroke [mm] & 105 \\
Cylinder volume [cc] & 115 \\
\hline
\end{tabular}

\subsection{Spray characteristics test}

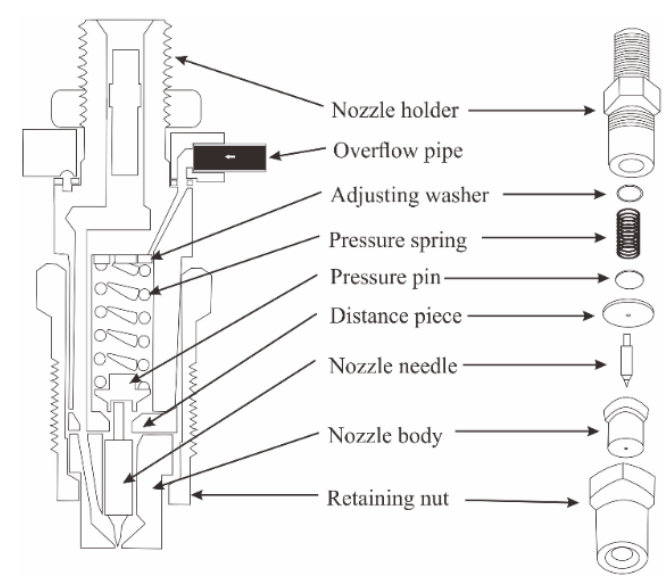

Figure 1. Detail injector geometry 
To find out the results of fuel atomization, spray characteristic tests were carried out using a Bosch pump tester with biodiesel fuel. Figure 1 shows the injector used in a developed DI 20C biodiesel engine prototype. Then the injection pressure variation is performed by setting the rotation in adjusting screw on the injector until the injection pressure will be tested, where injection pressure will be seen in the pressure gauge. The pressure variations in this study were 200 , 210,220 , and $230 \mathrm{~kg} / \mathrm{cm}^{2}$.

This test was carried out at the combustion and energy system laboratory of the mechanical engineering department, ITS Surabaya. Figure 2 shows the fuel spray characteristic test series. After testing, the length of penetration and spray angle of the fuel will be measured, and the calculation of the average droplet size $(S M D)$ with the formula approach from Lefebvre [14] is as follows:

$$
\mathrm{SMD}=2.25 \sigma^{0.25} \mu_{L}^{0.25} \dot{\mathrm{m}}_{L}^{0.25} \Delta P_{L}^{-0.5} \rho_{L}^{-0.25}
$$

\subsection{Experimental procedures}

The study was carried out experimentally on a diesel engine with a constant speed of $2000 \mathrm{rpm}$. This test is carried out on a developed DI 20C biodiesel engine prototype with the main shaft that has been coupled directly with the electrical generator as an electrical dynamometer. Data retrieval was carried out on each variation of load-tested, which is 1000 watt (low load), 4000 watt (medium load), and 7000 watts (high load) with an increment of 3000 watts.

All measuring equipment has been installed in accordance with the research scheme as shown in Figure 4. Fuel buratte meter is used to measure fuel consumption. Digital manometer is used to measure air flow rates. Ampere and voltmeter are used to measure current and voltage to get the value of engine performance. Smoke tester is used to measure smoke emission.
A thermometer is used to measure the operational temperature of the engine.

The first test was to the optimization of the injection pressure on a developed DI 20C biodiesel engine prototype. Injection pressure is varied by adding an adjusting washer to the injector, as shown in Figure 1. Each additional $0.1 \mathrm{~mm}$ of adjusting washer thickness increases injection pressure by 10 $\mathrm{kg} / \mathrm{cm}^{2}$ and then spray testing was carried out, as shown in Figure 2. After the spray test is carried out, then the engine performance and emissions are tested in the engine with a predetermined injection pressure variation.

Then the second test was to the optimization of the injection timing. Variation injection timing was done by adding and reducing the thickness of the shim at the fuel injector pump, as in Figure 3. Adding thickness to the shim plate means retarding the injection timing, while reducing the thickness of the plate shim means advancing the injection timing. With a reduction or addition of $0.1 \mathrm{~mm}$ to the thickness of the shim plate can change the injection timing of $1^{\circ}$ BTDC.

The parameters of the research on a developed DI 20C biodiesel engine prototype can be explained in Table 3 below:

Table 3. Test parameters on a developed DI 20C biodiesel engine prototype

\begin{tabular}{cccc}
\hline $\begin{array}{c}\text { Speed } \\
{[\mathbf{r p m}]}\end{array}$ & Load & $\begin{array}{c}\text { Injection pressure } \\
{\left[\mathbf{k g} / \mathbf{c m}^{2}\right]}\end{array}$ & $\begin{array}{c}\text { Injection } \\
\text { timing } \\
{\left[{ }^{\circ} \text { BTDC] }\right.}\end{array}$ \\
\hline 2000 & $\begin{array}{c}\text { low, medium, } \\
\text { high } \\
\text { low, medium, } \\
\text { high }\end{array}$ & $200,210,220,230$ & 20 \\
2000 & 230 & $16,18,20,22$ \\
\hline
\end{tabular}

The testing scheme on a developed DI 20C biodiesel engine prototype is shown in Figure 4.

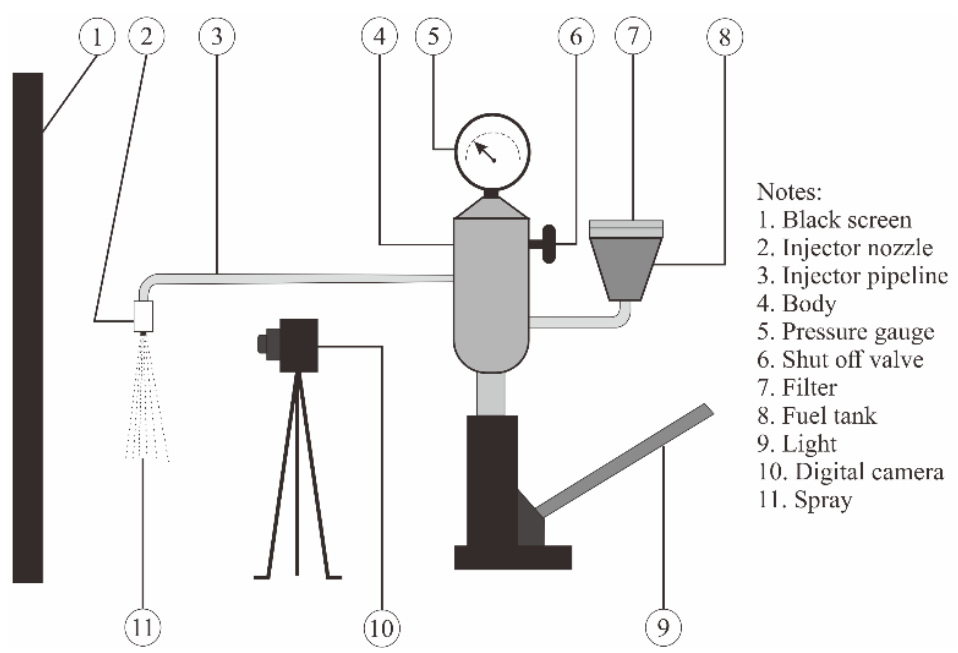

Figure 2. Schematic of spray characteristic testing

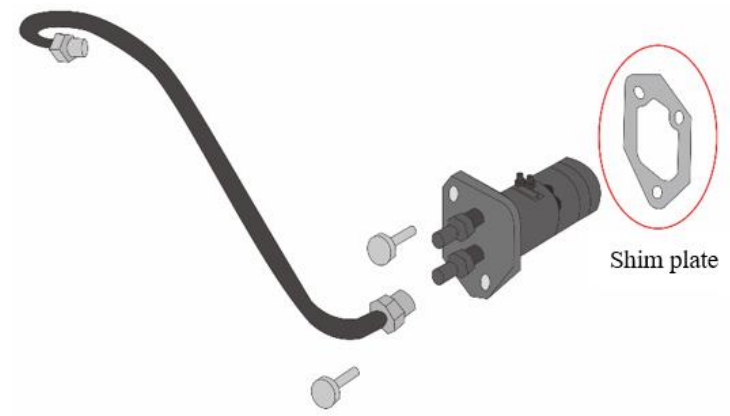

Figure 3. Setting the injection timing at the injection pump by adding a shim plate 


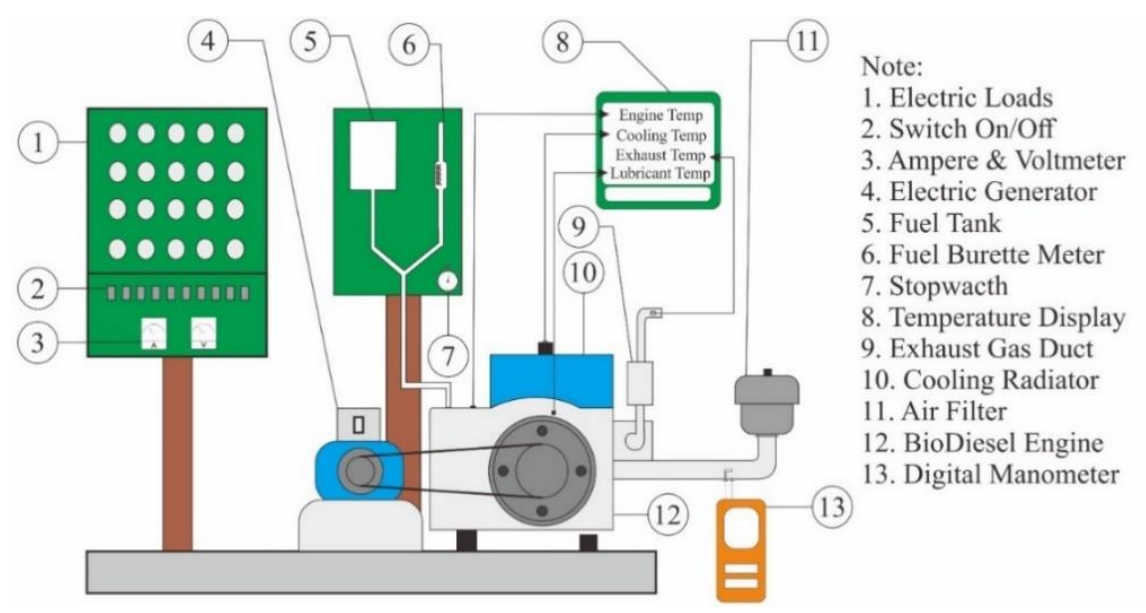

Figure 4. Schematic of the engine performance test

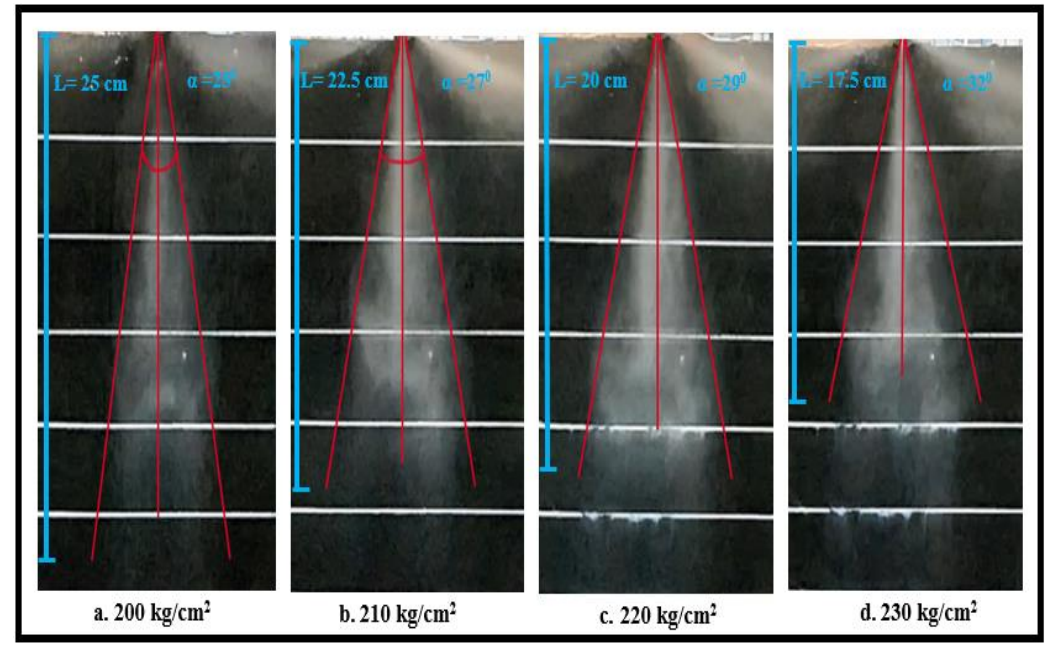

Figure 5. The visualization of sprays characteristics of biodiesel fuels

\section{RESULTS AND DISCUSSION}

The analysis of this study was carried out by compiling the results of the spray characteristics and experimental results of the performance test and exhaust emission test.

\subsection{Result of spray injection characteristics test}

Based on the properties of biodiesel that we have acknowledged, in the previous paragraph. Higher viscosity causes higher flow momentum so that the spray penetration length becomes longer, while higher surface tension makes it difficult for droplets of fuel to become smaller granules (secondary break up), which will then spread in all directions. This spread causes the contact surface of droplet fuel with less air, so the evaporation that occurs will be longer than the fuel, which has a higher surface tension value.

Figure 5 shows a visualization of the characteristics of the fuel sprays with different injection pressures. Under standard fuel injection pressure conditions of $200 \mathrm{~kg} / \mathrm{cm}^{2}$, the spray penetration length is $25 \mathrm{~cm}$, and the spray spread angle is $25^{\circ}$. Then by increasing injection pressure, the spray penetration length decreases and the spray spread angle is increased so as to produce more atomization good. Optimal injection pressure is obtained of $230 \mathrm{~kg} / \mathrm{cm}^{2}$, which is characterized by a $30 \%$ reduction in spray penetration length. This causes the flow momentum to be shorter thereby reducing fuel buildup in the combustion chamber wall. While the spray spread angle increased by $21.9 \%$, causing an increase in the contact surface of the fuel droplet with the combustion air. This causes more mixing, evaporation and atomization of the fuel so that the combustion process becomes more perfect

The increased of injection pressure is due to the addition of the thickness of the injector washer. Table 4 shows the results of Sauter Mean Diameter (SMD) calculations for all loads using Eq. (1).

Table 4. The results of Sauter mean diameter (SMD) calculations at all loads

\begin{tabular}{ccccc}
\hline \multirow{2}{*}{$\begin{array}{c}\text { Electrical } \\
\text { load }\end{array}$} & \multicolumn{4}{c}{ SMD $(\boldsymbol{\mu m})$} \\
\cline { 2 - 5 } & $\mathbf{2 0 0}$ & $\mathbf{2 1 0}$ & $\mathbf{2 2 0}$ & $\mathbf{2 3 0}$ \\
\hline Low & 0.0138 & 0.0133 & 0.0130 & 0.0125 \\
Medium & 0.0148 & 0.0144 & 0.0139 & 0.0134 \\
High & 0.0161 & 0.0156 & 0.0150 & 0.0144 \\
\hline
\end{tabular}

The calculation of the $S M D$ equation explains that increasing injection pressure can reduce the $S M D$ value at all engine loads, where the lowest $S M D$ value is obtained at an injection pressure of $230 \mathrm{~kg} / \mathrm{cm}^{2}$.

The percentage decrease in $S M D$ at low, medium and high loads were $9.4 \%, 9.5 \%$, and $10.6 \%$ of the standard injection pressure, respectively. This shows that the addition of 
injection pressure will accelerate the spray evolution process, which is characterized by a smaller $S M D$ value which will result in more active and faster atomization. Droplets break up more quickly into smaller secondary droplets, making it easier for evaporation and mixing with combustion air. This will initiate the formation of a homogeneous mixture and encourage a greater ignition process as explained by previous studies [15]. Mahanggi et al. [8] explained that increasing the fuel injection pressure resulted in better spray atomization and a larger spray angle. This improved atomization process tends to reduce the duration of the ignition delay, the duration of premixed combustion and diffusion combustion, and increase the total of heat release $[6,16]$.

Table 4 also shows the trend that the greater the engine load, the higher the SMD value. This is due to the increase in engine load, it requires more fuel consumption.

\subsection{Effects of injection pressure}

This test was carried out to determine the performance and emissions with injection pressure variations on a developed DI 20C biodiesel engine prototype using CPO biodiesel (B100) fuel at low, medium, and high loads. The final results of this study were performance and exhaust emissions, including power, brake thermal efficiency (BTE), specific fuel consumption (SFC), air-fuel ratio, and smoke opacity, then also displayed temperatures including the engine body, lubricants, cooling water and exhaust gases.

Figure 6 shows that the performance of a developed DI 20C biodiesel engine prototype using diesel fossil fuels was better than using biodiesel fuels at all loads. It can be seen from the power, and thermal efficiency values were higher and lower SFC values from using biodiesel fuel. This is because CPO biodiesel fuel has a low calorific value so that the amount of fuel consumed is large, so the mixture becomes richer compared to diesel fossil fuel, and also high viscosity, density, and surface tension are the reason for the decline in engine performance using biodiesel fuel $[17,18]$.

Figure 6 also explains the effect of injection pressure on power, specific fuel consumption (SFC), and thermal efficiency (BTE) at all engine loads. All engine loads show that the trendline graphs for each parameter were more likely to be the same with the variation of injection pressure. With increasing injection pressure improves power, BTE values, and lowering SFC value at all engine loads with an optimal injection pressure of $230 \mathrm{~kg} / \mathrm{cm}^{2}$.

The low load, the maximum power value reaches $1.084 \mathrm{~kW}$ with a percentage increase of $6.2 \%$, the minimum specific fuel consumption value reaches $0.79 \mathrm{~kg} / \mathrm{kW}$.h with a percentage decrease of $13.3 \%$, and then the thermal efficiency value reaches $10.7 \%$ with a percentage increase of $13.4 \%$ from standard injection pressure as shown in Figure 6a. The medium load, the maximum power value reaches $3.673 \mathrm{~kW}$ with a percentage increase of $1.2 \%$, the minimum specific fuel consumption value reaches $0.326 \mathrm{~kg} / \mathrm{kW}$.h with a percentage decrease of $12.12 \%$, and then the thermal efficiency value reaches $25.9 \%$ with a percentage increase of $12.15 \%$ from standard injection pressure as shown in Figure 6b. The high load, the maximum power value reaches $6.55 \mathrm{~kW}$ with a percentage increase of $1 \%$, the minimum specific fuel consumption value reaches $0.255 \mathrm{~kg} / \mathrm{kW}$.h with a percentage decrease of $16.4 \%$, and then the thermal efficiency value reaches $33.2 \%$ with a percentage increase of $18.1 \%$ from standard injection pressure as shown in Figure $6 \mathrm{c}$. This is due to the shorter flow momentum, which reduces fuel buildup on the piston crown and a greater spread of fuel spray so that it is distributed to all combustion chambers and allows the material to mix with more air.

Then also the spray evolution process is faster due to better atomization so that the process of fuel evaporation is improved, and the mixing of fuel and air is more homogeneous, as seen in the visualization of Figure 3. This will increase engine power, which has an effect on increasing thermal efficiency, as explained in previous studies [19]. The specific fuel consumption value of a developed DI 20C biodiesel engine prototype using biodiesel fuel is higher than diesel fossil fuel, and this is because the density value of biodiesel fuel is higher, as explained in previous studies [3, 18]. The addition of injection pressure affects the decrease in the value of SFC. This is due to an increase in engine power so that the engine is more efficient in consuming fuel.

Figure 7 shows the air-fuel ratio and smoke emissions in a developed DI 20C biodiesel engine prototype using diesel fossil fuels higher than using biodiesel fuels, while the exhaust gas temperature is lower at all loads. The reduction in an airfuel ratio in engines using biodiesel fuel was caused by the amount of fuel used more because of the lower calorific value. The reduction in smoke emissions due to biodiesel fuels has a lower carbon value than fossil fuels. Increased exhaust gas temperature using biodiesel fuel due to the amount of oxygen content, which is more so that it increases the combustion process [3, 17].

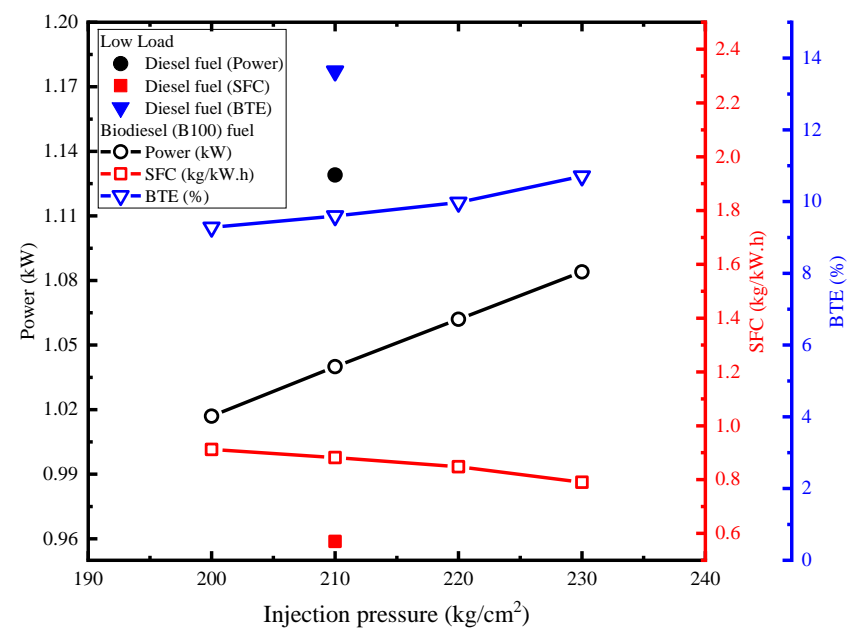

(a) At low load

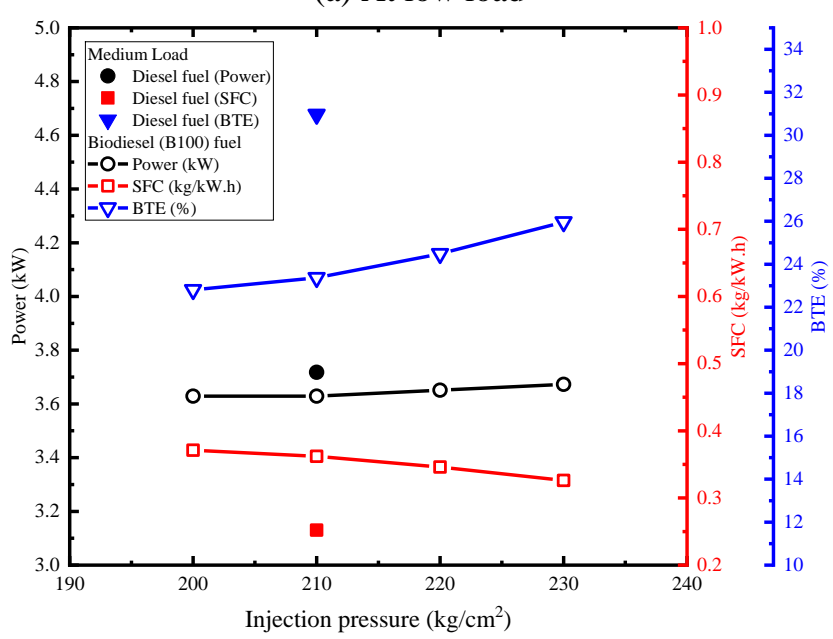

(b) At medium load 


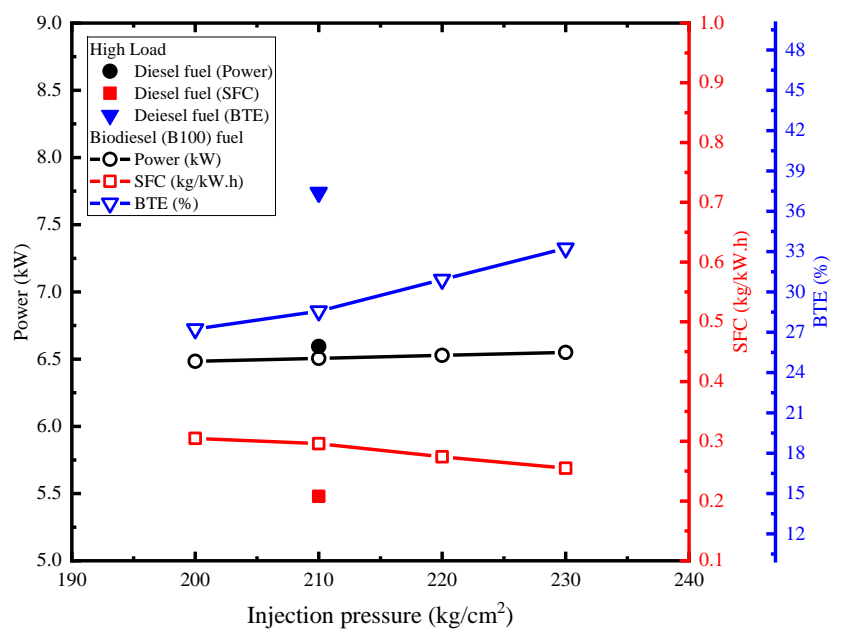

(c) At high load

Figure 6. Effect of injection pressure on power, SFC and BTE

Figure 7 also shows that the effect of injection pressure on the air-fuel ratio (AFR), smoke emissions, and exhaust gas temperatures at all loads. All engine loads show that the trendline graphs for each parameter were more likely to be the same with a variation of injection pressure. Increasing the injection pressure is an optimal value of $230 \mathrm{~kg} / \mathrm{cm}^{2}$ can improve the value of the air-fuel ratio, smoke emissions, and exhaust gas temperatures on a developed DI 20C biodiesel engine prototype using biodiesel fuel at all loads.

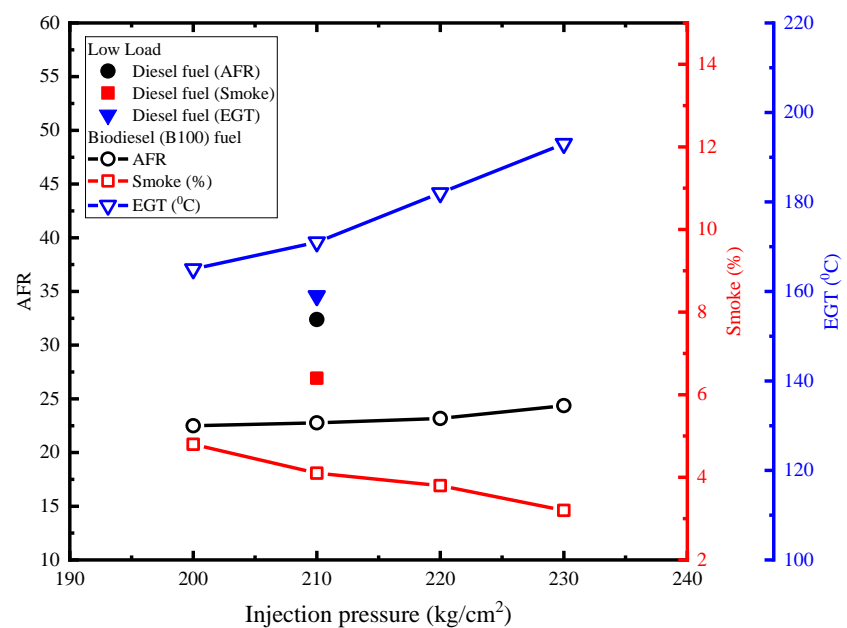

(a) At low load

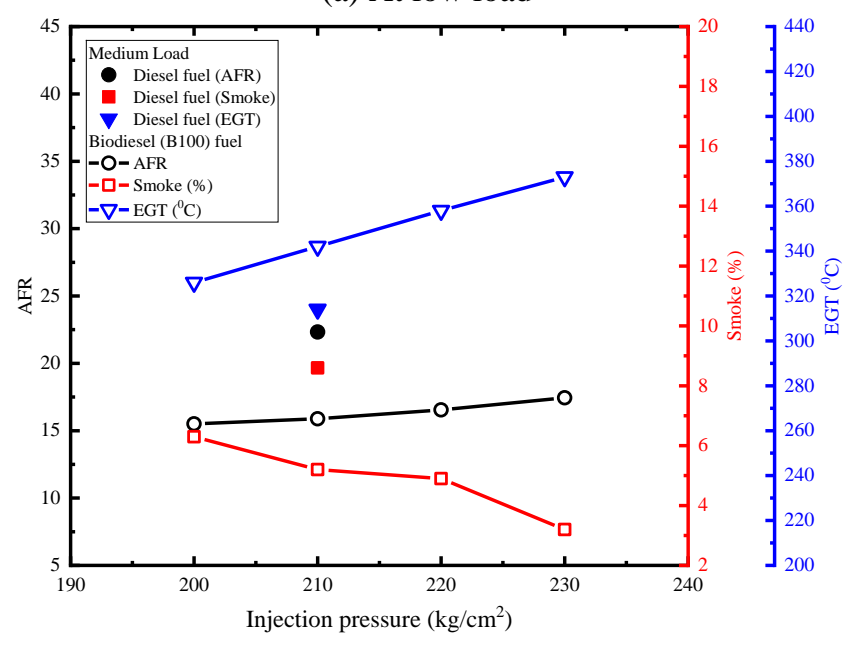

(b) At medium load

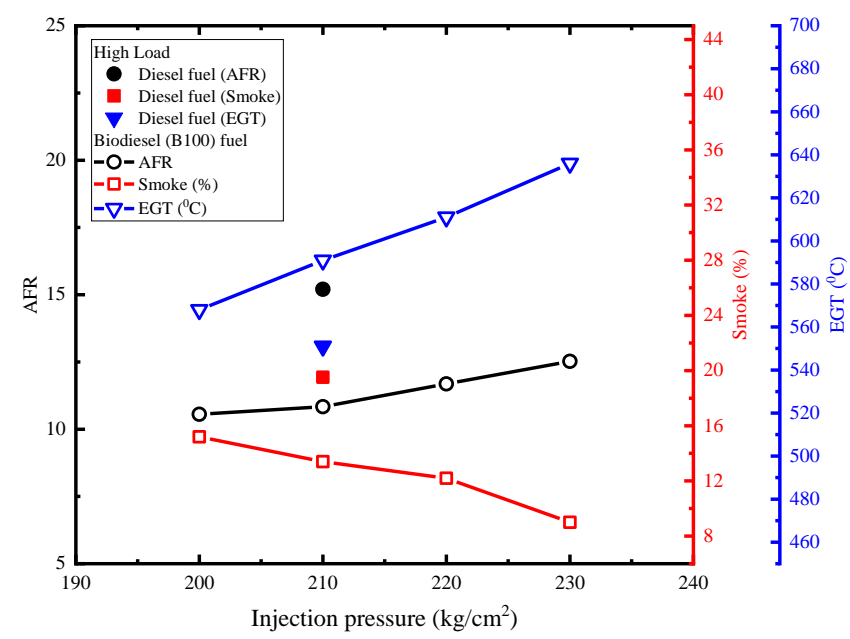

(c) At high load

Figure 7. Effect of injection pressure on AFR, smoke emission, and EGT

The low load, the maximum air-fuel ratio value reaches 24.3 with a percentage increase of $7.7 \%$, the minimum smoke emission value reaches $3.2 \%$ with a percentage decrease of $33.3 \%$, and then the maximum exhaust gas temperature value reaches $193^{\circ} \mathrm{C}$ with a percentage increase of $14.5 \%$ from standard injection pressure as shown in Figure $7 \mathrm{a}$. The medium load, the maximum air-fuel ratio value reaches 17.4 with a percentage increase of $11.1 \%$, the minimum smoke emission value reaches $3.2 \%$ with a percentage decrease of $49.2 \%$, and then the maximum exhaust gas temperature value reaches $373^{\circ} \mathrm{C}$ with a percentage increase of $12.6 \%$ from standard injection pressure as shown in Figure $7 \mathrm{~b}$. The high load, the maximum air-fuel ratio value reaches 12.5 with a percentage increase of $15.7 \%$, the minimum smoke emission value reaches $9 \%$ with a percentage decrease of $40.7 \%$, and then the maximum exhaust gas temperature value reaches $636^{\circ} \mathrm{C}$ with a percentage increase of $10.7 \%$ from standard injection pressure as shown in Figure 7c.

The increase in an air-fuel ratio by increasing injection pressure is caused by a decrease in SFC value due to better atomization [20]. The reduction in smoke emissions by increasing the injection pressure using biodiesel fuel is caused by an increase in atomization and evaporation and also a higher amount of oxygen so that combustion is better [19]. The increase in exhaust gas temperature by increasing the injection pressure using biodiesel fuel is due to better atomization so that the mixing of fuel and air is more homogeneous and produces maximum combustion, which resulting in an increase in combustion temperature.

Figure 8 shows the difference in temperature in a developed DI 20C biodiesel engine prototype between using diesel fossil fuels and biodiesel fuels. This temperature consists of engine body temperature, lubricant temperature, and cooling water temperature. It is seen that the value of the three temperatures using biodiesel fuel is higher than using fossil fuel at all engine loads. The increase of third temperatures is due to the amount of biodiesel fuel used more to offset the engine load. Thus, the amount of oxygen content is more so that it increases the combustion process in the combustion chamber $[3,17]$.

Figure 8 also shows the effect of injection pressure on engine body temperature, lubricant temperature, and cooling water temperature at all load. All engine loads show that the trendline graphs for each parameter were more likely to be the 
same with a variation of injection pressure. Increasing the injection pressure is an optimal value of $230 \mathrm{~kg} / \mathrm{cm}^{2}$ can improve the value of the three temperatures on a developed DI 20C biodiesel engine prototype using biodiesel fuel at all loads.

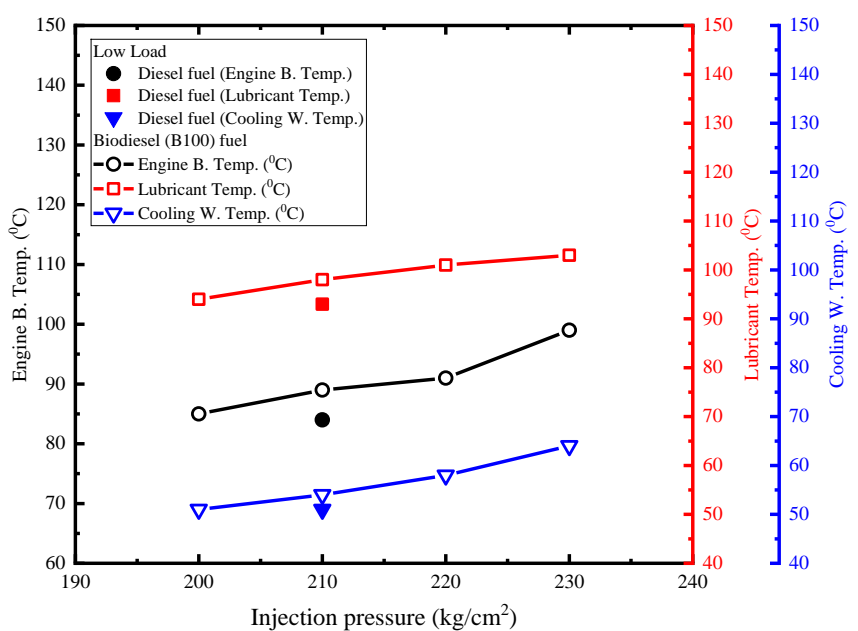

(a) At low load

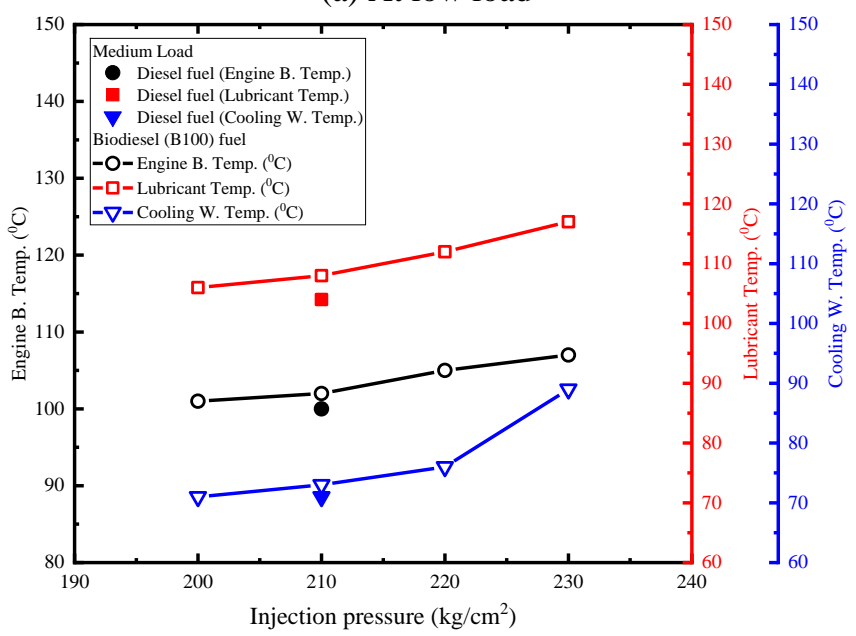

(b) At medium load

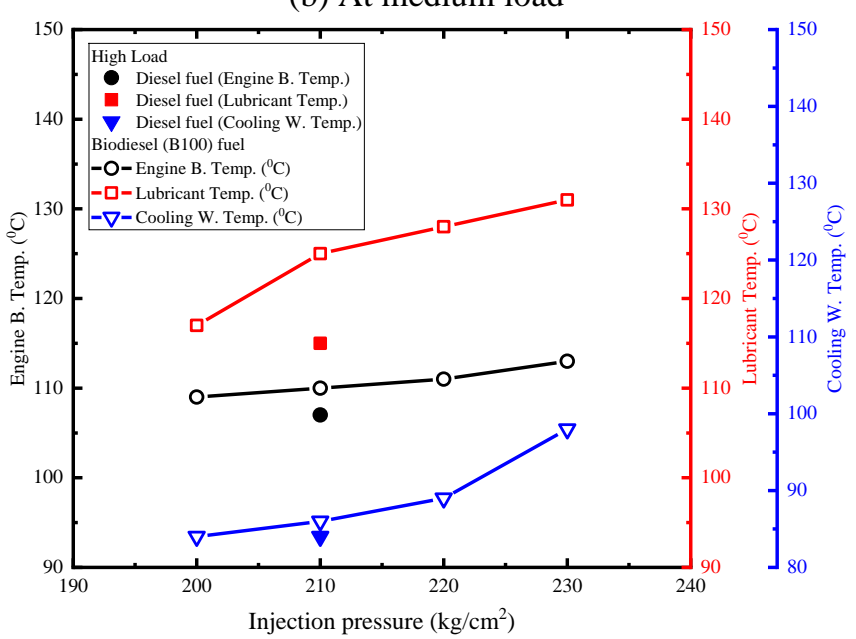

(c) At high load

Figure 8. Effect of injection pressure on engine body temperature, lubricant temperature, and cooling water temperature

The low load, maximum engine body temperature value reaches $99^{\circ} \mathrm{C}$ with a percentage increase of $14.1 \%$, the maximum lubricant temperature value reaches $103^{\circ} \mathrm{C}$ with a percentage increase of $8.7 \%$, and the cooling water temperature value reaches $64^{\circ} \mathrm{C}$ with a percentage increase of $25.5 \%$ from standard injection pressure as shown in Figure 8a. The medium load, maximum engine body temperature value reaches $107^{\circ} \mathrm{C}$ with a percentage increase of $5.6 \%$, the maximum lubricant temperature value reaches $117^{\circ} \mathrm{C}$ with a percentage increase of $9.4 \%$, and the cooling water temperature value reaches $89^{\circ} \mathrm{C}$ with a percentage increase of $20.2 \%$ from standard injection pressure as shown in Figure 8b. The high load, maximum engine body temperature value reaches $113^{\circ} \mathrm{C}$ with a percentage increase of $3.5 \%$, the maximum lubricant temperature value reaches $131^{\circ} \mathrm{C}$ with a percentage increase of $10.7 \%$, and the cooling water temperature value reaches $98^{\circ} \mathrm{C}$ with a percentage increase of $14.3 \%$ from standard injection pressure as shown in Figure 8c. Increasing the injection pressure causes complete combustion, which influences the temperature rise because it results from better atomization so that the mixing of biodiesel fuel with air is more homogeneous. Then also evaporation from droplets is better because of the presence of more oxygen [21].

\subsection{Effects of injection timing}

This section discusses the effect of injection timing on engine performance, emissions, and temperature.

Figure 9 shows that the performance of a developed DI 20C biodiesel engine prototype using diesel fossil fuel was better than using biodiesel fuels at all loads. It can be seen from the power, and thermal efficiency values were higher and lower SFC values of a developed DI 20C biodiesel engine prototype using biodiesel fuel. The decrease in engine performance is influenced by the properties of the biodiesel fuel itself, such as low calorific values so that chemical energy is converted to mechanical energy is less. Biodiesel has a high density and viscosity and a high surface tension so that atomization is not good, and the evaporation of fuel is low so that the quality of the mixture between fuel and air is poorer. Besides that, biodiesel fuel has a high cetane number so that the ignition delay period is shorter and allows faster start of combustion resulting in the peak of premixed combustion being too close to the upper dead point (TDC) on the cylinder so that it affects the reduction of diffusion combustion with a longer combustion duration [18].

Figure 9 also explains the effect of injection timing on power, specific fuel consumption (SFC), and thermal efficiency (BTE) at all engine loads. All engine loads show that the trendline graphs for each parameter were more likely to be the same with a variation of injection timing. With retarded injection timing improves power, BTE values and lowering SFC value at all engine loads with an optimal injection timing of $16^{\circ}$ BTDC.

The low load, the maximum power value reaches $1.106 \mathrm{~kW}$ with a percentage increase of $2.4 \%$, the minimum specific fuel consumption value reaches $0.748 \mathrm{~kg} / \mathrm{kW}$.h with a percentage decrease of $11 \%$, and then the thermal efficiency value reaches $11.3 \%$ with a percentage increase of $10 \%$ from the injection timing being advanced of $22^{\circ}$ BTDC as shown in Figure 9a. The medium load, the maximum power value reaches 3.695 $\mathrm{kW}$ with a percentage increase of $2.3 \%$, the minimum specific fuel consumption value reaches $0.284 \mathrm{~kg} / \mathrm{kW}$.h with a percentage decrease of $20.8 \%$, and then the thermal efficiency value reaches $29.7 \%$ with a percentage increase of $20.7 \%$ from the injection timing being advanced of $22^{\circ}$ BTDC as shown in Figure $9 \mathrm{~b}$. The high load, the maximum power value reaches $6.572 \mathrm{~kW}$ with a percentage increase of $3.9 \%$, the minimum 
specific fuel consumption value reaches $0.236 \mathrm{~kg} / \mathrm{kW}$.h with a percentage decrease of $13.8 \%$, and then the thermal efficiency value reaches $35.9 \%$ with a percentage increase of $13.9 \%$ from the injection timing being advanced of $22^{\circ}$ BTDC as shown in Figure 9c. This is because the peak of the premixed combustion moves slightly away from the TDC following the peak of the combustion premixed of diesel fossil fuel, so that the diffusion combustion is optimal, due to retarded of the injection timing. Then also, if retarded of the injection timing, then the pressure and temperature at the end of the compression stroke are higher so that the premixed combustion becomes maximum. In addition, the atomization is better because the injection pressure used is optimal at 230 $\mathrm{kg} / \mathrm{cm}^{2}$ at various injection timing variations. Thus, generating greater power with more efficient fuel consumption thereby increasing the value of thermal efficiency.

Figure 9 also explains the effect of injection timing on power, specific fuel consumption (SFC), and thermal efficiency (BTE) at all engine loads. All engine loads show that the trendline graphs for each parameter were more likely to be the same with a variation of injection timing. With retarded injection timing improves power, BTE values and lowering SFC value at all engine loads with an optimal injection timing of $16^{\circ} \mathrm{BTDC}$.

The low load, the maximum power value reaches $1.106 \mathrm{~kW}$ with a percentage increase of $2.4 \%$, the minimum specific fuel consumption value reaches $0.748 \mathrm{~kg} / \mathrm{kW}$.h with a percentage decrease of $11 \%$, and then the thermal efficiency value reaches $11.3 \%$ with a percentage increase of $10 \%$ from the injection timing being advanced of $22^{\circ}$ BTDC as shown in Figure 9a. The medium load, the maximum power value reaches 3.695 $\mathrm{kW}$ with a percentage increase of $2.3 \%$, the minimum specific fuel consumption value reaches $0.284 \mathrm{~kg} / \mathrm{kW}$.h with a percentage decrease of $20.8 \%$, and then the thermal efficiency value reaches $29.7 \%$ with a percentage increase of $20.7 \%$ from the injection timing being advanced of $22^{\circ} \mathrm{BTDC}$ as shown in Figure $9 \mathrm{~b}$. The high load, the maximum power value reaches $6.572 \mathrm{~kW}$ with a percentage increase of $3.9 \%$, the minimum specific fuel consumption value reaches $0.236 \mathrm{~kg} / \mathrm{kW}$.h with a percentage decrease of $13.8 \%$, and then the thermal efficiency value reaches $35.9 \%$ with a percentage increase of $13.9 \%$ from the injection timing being advanced of $22^{\circ}$ BTDC as shown in Figure 9c. This is because the peak of the premixed combustion moves slightly away from the TDC following the peak of the combustion premixed of diesel fossil fuel, so that the diffusion combustion is optimal, due to retarded of the injection timing. Then also, if retarded of the injection timing, then the pressure and temperature at the end of the compression stroke are higher so that the premixed combustion becomes maximum. In addition, the atomization is better because the injection pressure used is optimal at 230 $\mathrm{kg} / \mathrm{cm}^{2}$ at various injection timing variations. Thus, generating greater power with more efficient fuel consumption thereby increasing the value of thermal efficiency.

Whereas by advancing the injection timing by $22^{\circ} \mathrm{BTDC}$, resulting in a decrease in power, SFC and BTE. This is because the pressure and air temperature are still low when the injection starts [22] and causes the fuel not to burn completely and produce incomplete combustion.

Figure 10 shows the air-fuel ratio and smoke emissions in a developed DI 20C biodiesel engine prototype using diesel fossil fuels higher than using biodiesel fuels, while the exhaust gas temperature is lower at all loads. The reduction in an airfuel ratio in engines using biodiesel fuel was caused by the amount of fuel used more because of the lower calorific value. The reduction in smoke emissions due to biodiesel fuel has a lower carbon value than fossil fuels. The increase in the temperature of the exhaust gas by using biodiesel fuel is due to the higher oxygen content in biodiesel. The existence of this oxygen then plays an active role in the oxidation process, so as a whole can improve the combustion process [17]. Increased exhaust gas temperature using biodiesel fuel due to the amount of oxygen content, which is more so that it increases the combustion process [17].

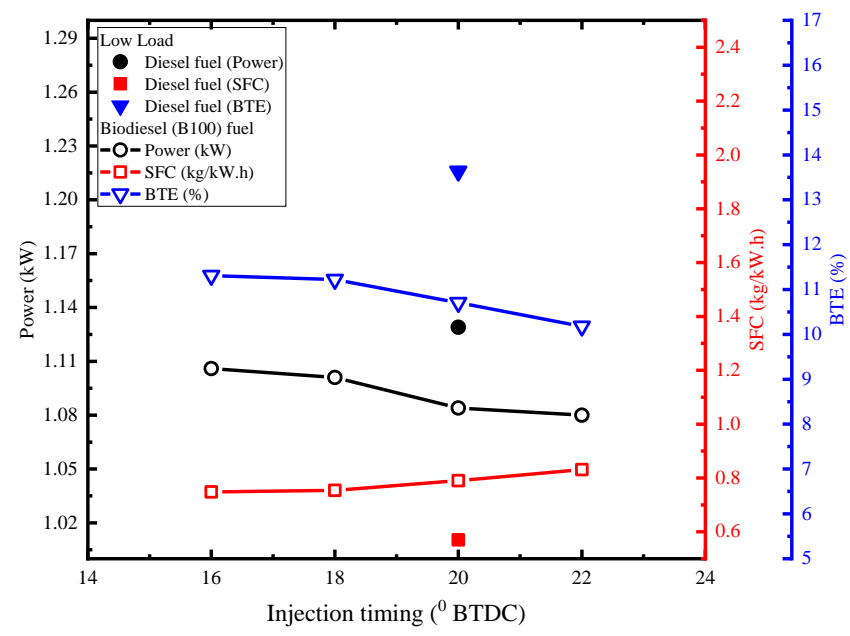

(a) At low load

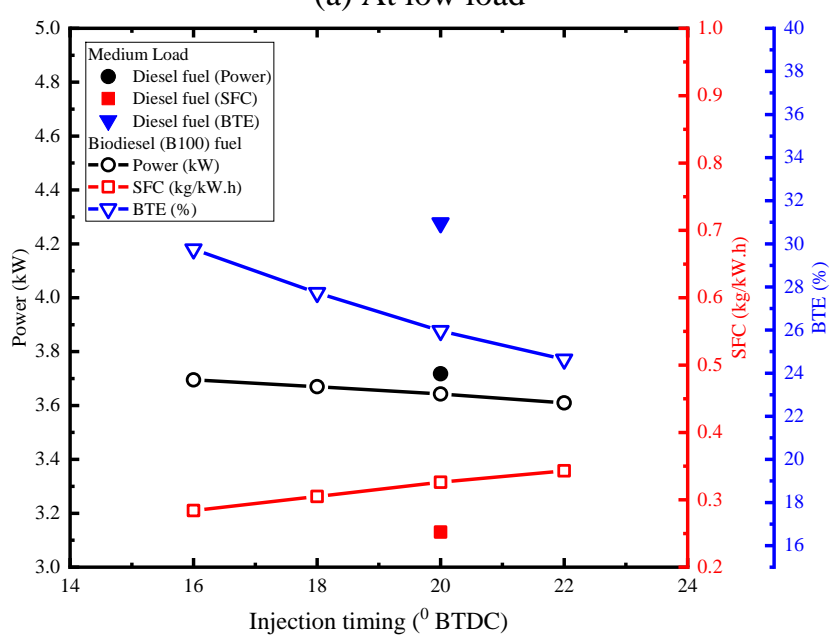

(b) At medium load

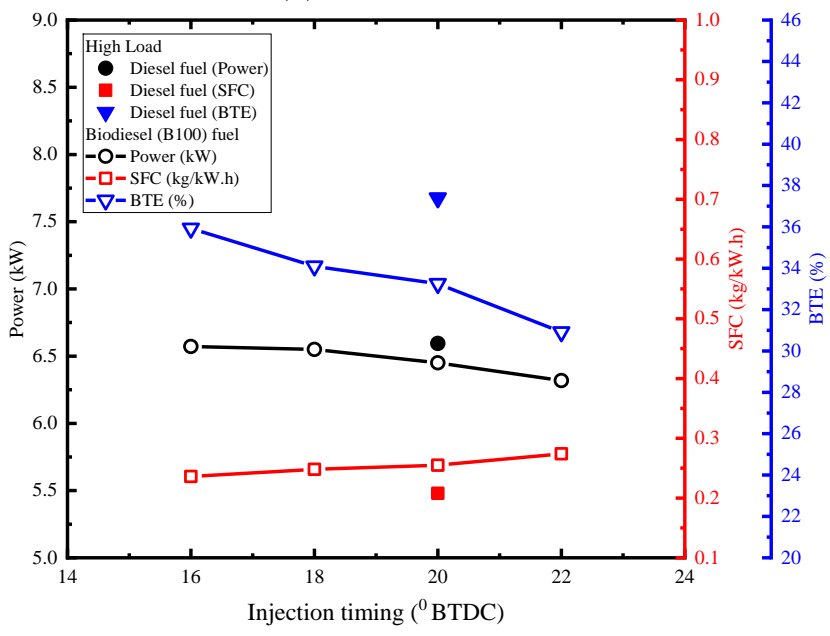

(c) At high load

Figure 9. Effect of injection timing on power, SFC, and BTE 


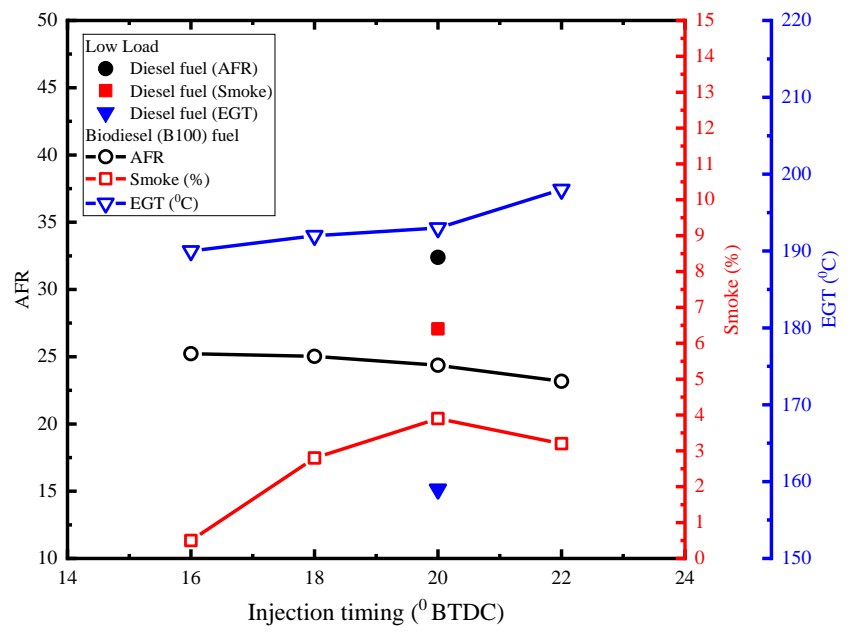

(a) At low load

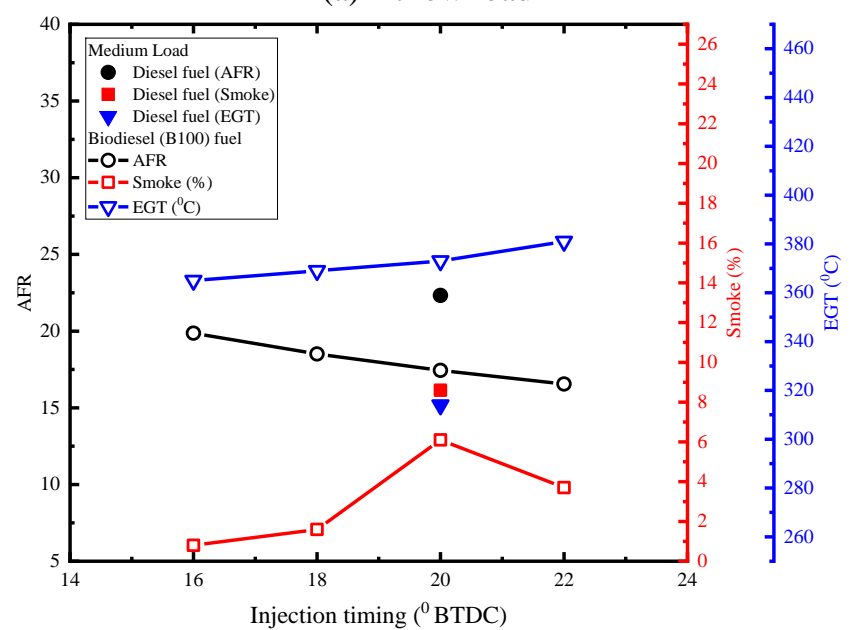

(b) At medium load

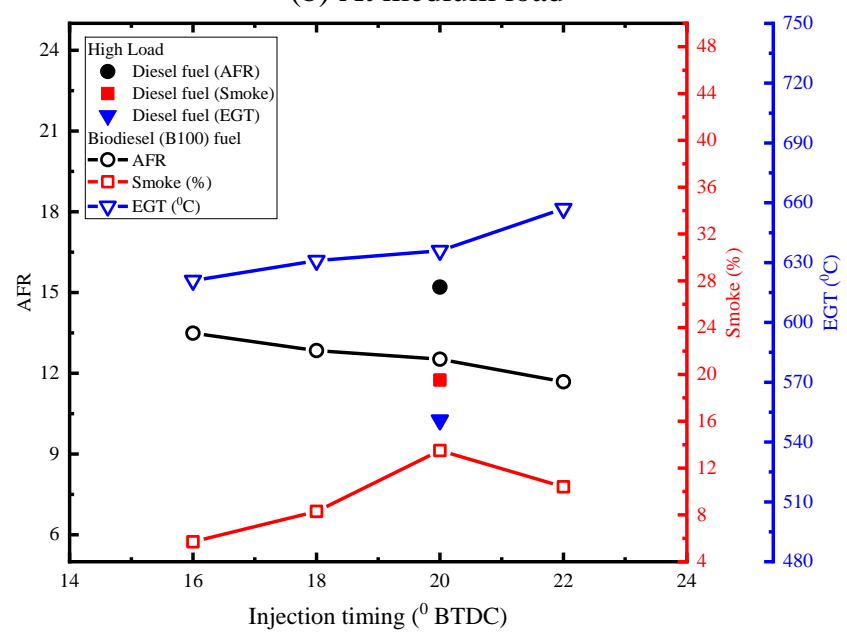

(c) At high load

Figure 10. Effect of injection timing on AFR, smoke emission, and EGT

Figure 10 also shows that the effect of injection timing on the air-fuel ratio (AFR), smoke emissions, and exhaust gas temperatures at all loads. All engine loads show that the trendline graphs for each parameter were more likely to be the same with a variation of injection timing. Retarded the injection timing is the optimal value of $16^{\circ} \mathrm{BTDC}$ can improve the value of the air-fuel ratio, smoke emissions, and exhaust gas temperatures on a developed DI 20C biodiesel engine prototype at all loads.

The low load, maximum air-fuel ratio value reaches 25.2 with a percentage increase of $8.1 \%$, the minimum smoke emission value reaches $0.5 \%$ with a percentage decrease of $84.4 \%$, and then minimum exhaust gas temperature value reaches $190^{\circ} \mathrm{C}$ with a percentage decrease of $4 \%$ from the injection timing being advanced of $22^{\circ}$ BTDC as shown in Figure 10a. The medium load, maximum air-fuel ratio value reaches 19.9 with a percentage increase of $16.7 \%$, the minimum smoke emission value reaches $0.8 \%$ with a percentage decrease of $78.4 \%$, and then minimum exhaust gas temperature value reaches $365^{\circ} \mathrm{C}$ with a percentage decrease of $4.2 \%$ from the injection timing being advanced of $22^{\circ}$ BTDC as shown in Figure 10b. The high load, maximum airfuel ratio value reaches 13.5 with a percentage increase of $13.4 \%$, the minimum smoke emission value reaches $5.7 \%$ with a percentage decrease of $45.2 \%$, and then minimum exhaust gas temperature value reaches $621{ }^{\circ} \mathrm{C}$ with a percentage decrease of $5.5 \%$ from the injection timing being advanced of $22^{\circ}$ BTDC as shown Figure 10c.

All loads, the value of the air-fuel ratio increases by retarded the injection timing at $16^{\circ} \mathrm{BTDC}$, while the value of smoke emissions and exhaust gas temperatures decreases by retarded the injection timing. This is due to the injection timing approaching TDC, and with high injection pressure, the atomization of fuel when sprayed gets better and is supported by high air pressure and temperature, resulting in low smoke opacity, EGT, and high AFR as well.

Whereas by advancing the injection timing by $22^{\circ}$ BTDC, resulting in a decrease in air-fuel ratio and Smoke Opacity, while the value of exhaust gas temperature increases. This is because the pressure and air temperature are still low when the injection starts [22] and causes the fuel not to burn completely and produce incomplete combustion. This result shows that the most effective angle to produce maximum power is the smallest angle. It can be believed that the higher cetane number on biodiesel fuel is very influential at high combustion rates as well and resulting in low smoke emission [23]. Krishnamoorthi et al. [24] reported that advanced injection timing reduces the ignition delay and leads to the accumulation of less fuel, thus increases the smoke opacity [24]. Song et al. [25] also reported that the use of biodiesel could reduce smoke opacity. This is because biodiesel is free of sulfur and aromatic. Smoke is produced from the dehydrogenation of polycyclic from aromatic processes. In addition, the unsaturated fatty acids in biodiesel also affect the combustion process. Because unsaturated fatty acids have a saturated vapor temperature that is smaller than diesel fossil fuel, so biodiesel is more volatile, and combustion can be completely [25].

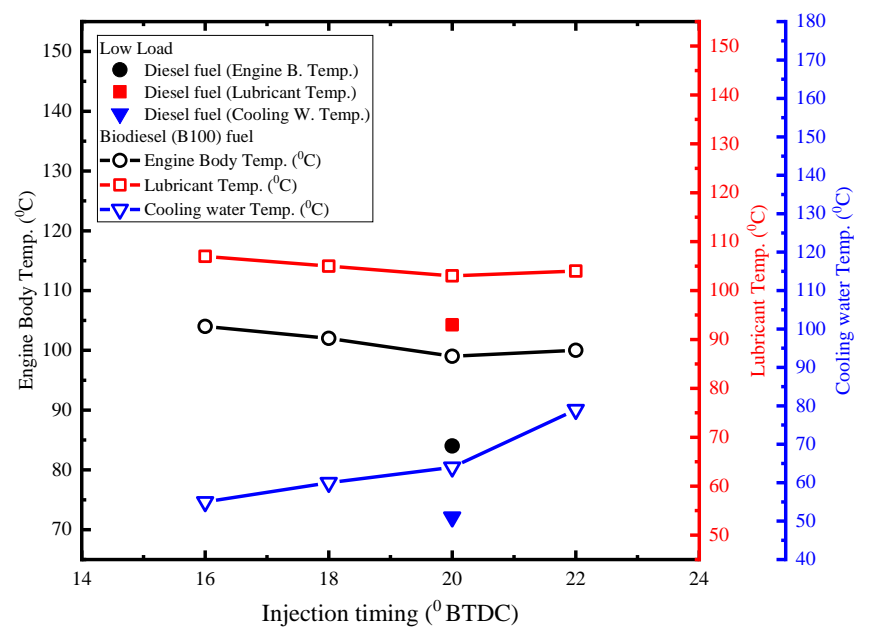

(a) At low load 


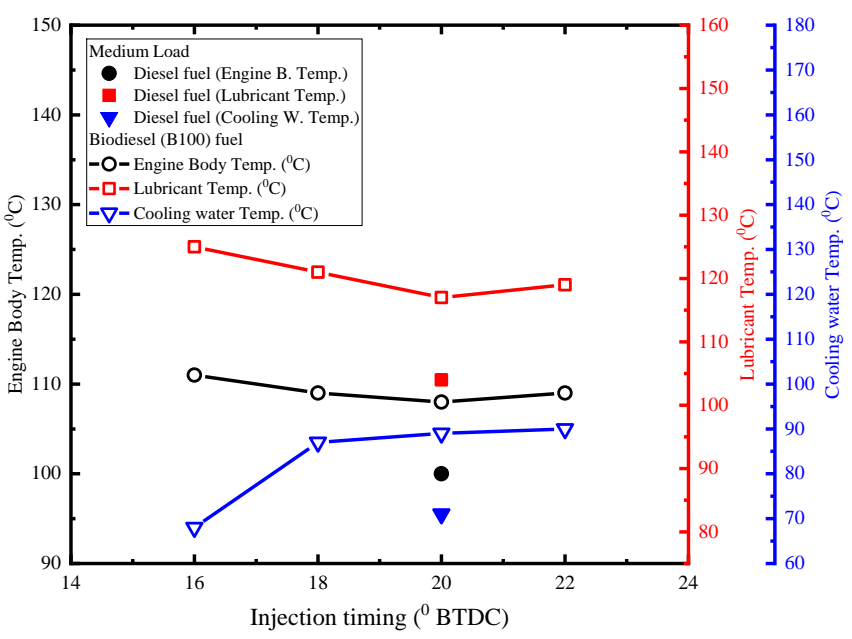

(b) At medium load

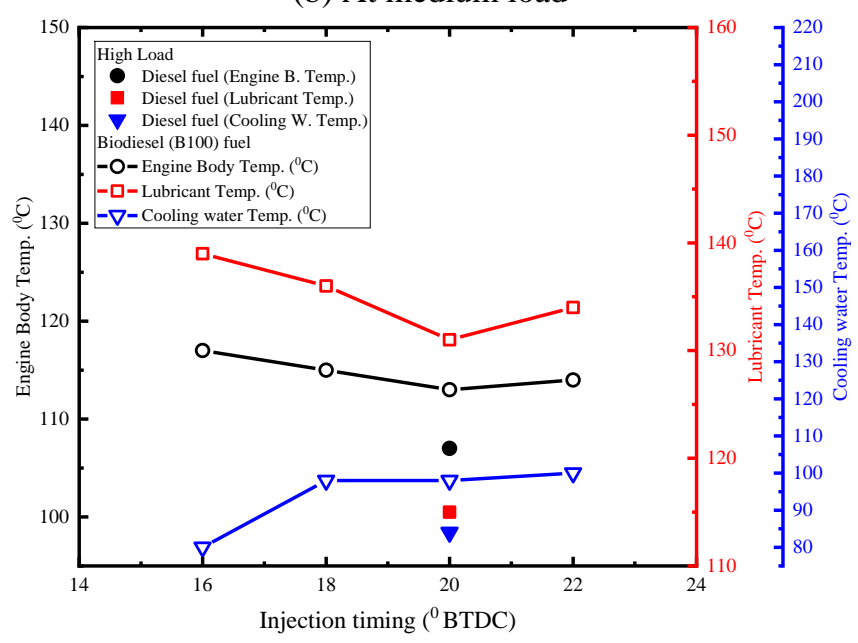

(c) At high load

Figure 11. Effect of injection timing on engine body temperature, lubricant temperature, and cooling water temperature

Figure 11 shows the difference in temperature on a developed DI 20C biodiesel engine prototype between using diesel fossil fuels and biodiesel fuels. This temperature consists of engine body temperature, lubricant temperature, and cooling water temperature. It appears that the value of three temperatures using biodiesel fuel is higher than using fossil fuels at all engine loads. The increase of third temperatures is due to the mass flow rate of biodiesel fuel more than fossil fuels to offset the engine load. Thus, the amount of oxygen content is more so that it increases the combustion process in the combustion chamber [17, 18].

The low load, maximum engine body temperature value reaches $104^{\circ} \mathrm{C}$ with a percentage increase of $3.8 \%$, the maximum lubricant temperature value reaches $107^{\circ} \mathrm{C}$ with a percentage increase of $2.8 \%$, and the cooling water temperature value reaches $55^{\circ} \mathrm{C}$ with a percentage decrease of $30.4 \%$ from the injection timing being advanced of $22^{\circ}$ BTDC as shown in Figure 11a. The medium load, maximum engine body temperature value reaches $111^{\circ} \mathrm{C}$ with a percentage increase of $1.8 \%$, the maximum lubricant temperature value reaches $125^{\circ} \mathrm{C}$ with a percentage increase of $4.8 \%$, and the cooling water temperature value reaches $68^{\circ} \mathrm{C}$ with a percentage decrease of $24.4 \%$ from the injection timing being advanced of $22^{\circ}$ BTDC as shown in Figure $11 \mathrm{~b}$. The high load, maximum engine body temperature value reaches $117^{\circ} \mathrm{C}$ with a percentage increase of $2.6 \%$, the maximum lubricant temperature value reaches $139^{\circ} \mathrm{C}$ with a percentage increase of $3.6 \%$, and the cooling water temperature value reaches $80^{\circ} \mathrm{C}$ with a percentage decrease of $20 \%$ from the injection timing being advanced of $22^{\circ}$ BTDC as shown in Figure 11c. The increase in engine body temperature and oil temperature when retarded the injection timing due to pressure and temperature at the end of compression is too high because it is approaching the top dead center (TDC), so resulting in maximum combustion and high temperatures.

Then, with advancing injection timing too early of $22^{\circ}$ BTDC, an increase in the three temperatures. The increase was due to better mixing of fuel and air so that premix combustion increased, and an increase in temperatures occurred.

\section{CONCLUSIONS}

Optimization of injection pressure and injection timing on fuel sprays, engine performances, and emissions on a developed DI 20C biodiesel engine prototype, it can be drawn several conclusions.

Fuel sprays can improve with the addition of injection pressure at the highest injection pressure of $230 \mathrm{~kg} / \mathrm{cm}^{2}$ with the following results:

$>\quad$ The length of spray penetration decreases by $30 \%$.

$>\quad$ Spray spread angle increased by $21.9 \%$.

$>$ Sauter Mean Diameter $(S M D)$ decreased by an average of $9.8 \%$.

Optimization of injection pressure was obtained at an injection pressure of $230 \mathrm{~kg} / \mathrm{cm}^{2}$ with the following results:

$>$ At low load where engine power increases by $6.2 \%$, specific fuel consumption (SFC) decreases by $13.3 \%$, thermal efficiency increases by $13.4 \%$, air and fuel ratio increase by $3.2 \%$ and smoke emissions decrease by $33.3 \%$, and exhaust gas temperatures increased by $14.5 \%$ of standard injection pressure.

$>$ At medium load where engine power increases by $1.2 \%$, specific fuel consumption (SFC) decreases by $12.12 \%$, thermal efficiency increases by $12.5 \%$, air and fuel ratio increase by $11.1 \%$ and smoke emissions decrease by $49.2 \%$, and exhaust gas temperatures increased by $12.6 \%$ of standard injection pressure.

$>\quad$ At high load where engine power increases by $1 \%$, specific fuel consumption (SFC) decreases by $16.4 \%$, thermal efficiency increases by $18.1 \%$, air and fuel ratio increase by $15.7 \%$ and smoke emissions decrease by $40.7 \%$, and exhaust gas temperatures increased by $10.7 \%$ of standard injection pressure.

Optimization of injection timing at injection pressure 230 $\mathrm{kg} / \mathrm{cm}^{2}$ obtained optimal injection timing of $16^{\circ}$ BTDC with the following results:

$>$ At low load where engine power increases by $2.4 \%$, specific fuel consumption (SFC) decreases by $11 \%$, thermal efficiency increases by $10 \%$, air and fuel ratio increase by $8.1 \%$ and smoke emissions decrease by $84.4 \%$ and exhaust gas temperatures decreased by $4 \%$ of the injection timing with the highest value.

$>\quad$ At medium load where engine power increases by $2.3 \%$, specific fuel consumption (SFC) decreases by $20.8 \%$, thermal efficiency increases by $20.7 \%$, air and fuel ratio increase by $16.7 \%$ and smoke 
emissions decrease by $78.4 \%$ and exhaust gas temperatures decreased by $4.2 \%$ of the injection timing with the highest value.

$>$ At high load where engine power increases by $3.9 \%$, specific fuel consumption (SFC) decreases by $13.9 \%$, thermal efficiency increases by $13.9 \%$, air and fuel ratio increase by $13.4 \%$ and smoke emissions decrease by $45.2 \%$ and exhaust gas temperatures increased by $5.5 \%$ of the injection timing with the highest value.

\section{ACKNOWLEDGMENT}

This research was carried out with the good cooperation of a developed DI 20C biodiesel engine prototype team, starting with the preparation of tools and materials, data collection, and data processing so that it could complete this article. Thank you to DRPM and DIKST ITS for the financial support for this research activity.

\section{REFERENCES}

[1] Alagu, K., Venu, H., Jayaraman, J., Raju, V.D., Subramani, L., Appavu, P., Dhanasekar, S. (2019). Novel water hyacinth biodiesel as a potential alternative fuel for existing unmodified diesel engine: Performance, combustion and emission characteristics. Energy, 179: 295-305. https://doi.org/10.1016/j.energy.2019.04.207

[2] Arumugam, A., Ponnusami, V. (2017). Production of biodiesel by enzymatic transesterification of waste sardine oil and evaluation of its engine performance. Heliyon, 3(12): e00486. http://dx.doi.org/10.1016/j.heliyon.2017.e00486

[3] Chaurasiya, P.K., Singh, S.K., Dwivedi, R., Choudri, R.V. (2019). Combustion and emission characteristics of diesel fuel blended with raw jatropha, soybean and waste cooking oils. Heliyon, 5(5): e01564. http://dx.doi.org/10.1016/j.heliyon.2019.e01564

[4] Rathore, Y., Ramchandani, D., Pandey, R.K. (2019). Experimental investigation of performance characteristics of compression-ignition engine with biodiesel blends of Jatropha oil \& coconut oil at fixed compression ratio. Heliyon, 5(11): e02717. http://dx.doi.org/10.1016/j.heliyon.2019.e02717

[5] Karmakar, R., Kundu, K., Rajor, A. (2018). Fuel properties and emission characteristics of biodiesel produced from unused algae grown in India. Petroleum Science, 15(2): 385-95. http://dx.doi.org/10.1007/s12182-017-0209-7

[6] Nautiyal, P., Subramanian, K.A., Dastidar, M.G., Kumar, A. (2019). Experimental assessment of performance, combustion and emissions of a compression ignition engine fuelled with Spirulina platensis biodiesel. Energy, 193:

116861 https://doi.org/10.1016/j.energy.2019.116861

[7] Nguyen, T., Pham, M., Le, T. (2020). Spray, combustion, performance and emission characteristics of a common rail diesel engine fueled by fi sh-oil biodiesel blends. Fuel, 269:

117108 . https://doi.org/10.1016/j.fuel.2020.117108

[8] Mahanggi, A.A.K., Sudarmanta, B., Hary, S. (2018). Experimental study on effect of injection pressure to spray characteristics, performance and emissions of diesel engine DI 20C using biodiesel fuel. The International Journal of Mechanical Engineering and Sciences, 2(1): 18-25.

[9] Sita, A.A, Sudarmanta, B. (2017). Studi eksperimen unjuk kerja mesin diesel sistem dual fuel dengan variasi tekanan penginjeksian pada injektor mesin yanmar $\mathrm{TF}$ 55R-DI. Jurnal Teknik ITS, 4(1): 1-6.

[10] Mutyalu, K.B., Das, V.C., Rao, S.K. (2018). Effect of fuel injection pressure on performance and emission characteristics of DI- CI engine with shea olein biodiesel. Materials Today: Proceedings, 5(1): 494-500. http://dx.doi.org/10.1016/j.matpr.2017.11.110

[11] Mendonca, S., Vas, J., Prabhu, R., Dsouza, R. (2016). Influence of injection timing on performance and combustion characteristics of simarouba biodiesel engine. International Journal of Innovative Research in Science, Engineering and Technology, 5(4): 4865-4872. https://doi.org/10.15680/IJIRSET.2016.0504038

[12] Hirkude, J., Belokar, V., Randhir, J. (2018). Effect of compression ratio, injection pressure and injection timing on performance and smoke emissions of CI engine fuelled with waste fried oil methyl esters - diesel blend. Materials Today: Proceedings, 5(1): 1563-70. http://dx.doi.org/10.1016/j.matpr.2017.11.247

[13] Tampubolon, A.S., Abdilla, A., Hapsari, D., Idoan, M., Pamela, S. (2020). Indonesia Clean Energy Outlook 2020 Report. Institute for Essential Services Reform (IESR): 1-72.

[14] Lefebvre, A., McDonell, V. (2017). Atomization and Sprays. Boca Raton: CRC Press. https://doi.org/10.1201/9781315120911

[15] Shervani-Tabar, M.T., Sheykhvazayefi, M., Ghorbani, M. (2013). Numerical study on the effect of the injection pressure on spray penetration length. Applied Mathematical Modelling, 37(14-15): 7778-7788. https://doi.org/10.1016/j.apm.2013.03.002

[16] Rajak, U., Verma, T.N. (2019). Influence of combustion and emission characteristics on a compression ignition engine from a different generation of biodiesel. Engineering Science and Technology, an International Journal, 23(1): 10-20. http://dx.doi.org/10.1016/j.jestch.2019.04.003

[17] Raman, L.A., Deepanraj, B., Rajakumar, S., Sivasubramanian, V. (2019). Experimental investigation on performance, combustion and emission analysis of a direct injection diesel engine fuelled with rapeseed oil biodiesel. Fuel, 246: 69-74. http://dx.doi.org/10.1016/j.fuel.2019.02.106

[18] Asokan, M.A., Senthur Prabu, S., Bade, P.K.K., Nekkanti, V.M., Gutta, S.S.G. (2019). Performance, combustion and emission characteristics of juliflora biodiesel fuelled DI diesel engine. Energy, 173: 883-892. http://dx.doi.org/10.1016/j.energy.2019.02.075

[19] Karikalan, L., Jacob, S., Baskar, S., Venugopal, S. (2019). Analyzing the influence of varied fuel injection pressure on diesel engine fueled with Karanja biodiesel. Materials Today: http://dx.doi.org/10.1016/j.matpr.2019.05.439

Proceedings.

[20] Hosamani, B.R., Katti, V.V. (2018). Experimental analysis of combustion characteristics of CI DI VCR engine using mixture of two biodiesel blend with diesel. Engineering Science and Technology, an International Journal,

21(4):

769-77. 
http://dx.doi.org/10.1016/j.jestch.2018.05.015

[21] Khandal, S.V., Banapurmath, N.R., Gaitonde, V.N. (2017). Effect of exhaust gas recirculation, fuel injection pressure and injection timing on the performance of common rail direct injection engine powered with honge biodiesel (BHO). Energy, 139: 828-841. http://dx.doi.org/10.1016/j.energy.2017.08.035

[22] Heywood, J.B. (1988). Internal combustion engine fundamentals: New York: McGraw-Hill.

[23] Agarwal, A.K., Dhar, A., Gupta, J.G., Kim, W.I., Choi, K., Lee, C.S., Park, S. (2015). Effect of fuel injection pressure and injection timing of Karanja biodiesel blends on fuel spray, engine performance, emissions and combustion characteristics. Energy Conversion and Management, 91:

302-314. http://dx.doi.org/10.1016/j.enconman.2014.12.004

[24] Krishnamoorthi, M., Malayalamurthi, R., Mohamed Shameer, P. (2018). RSM based optimization of performance and emission characteristics of DI compression ignition engine fuelled with diesel/aegle marmelos oil/diethyl ether blends at varying compression ratio, injection pressure and injection timing. Fuel, 221: 283-897. https://doi.org/10.1016/j.fuel.2018.02.070

[25] Song, J.T., Zhang, C.H. (2008). An experimental study on the performance and exhaust emissions of a diesel engine fuelled with soybean oil methyl ester. Proceedings of the Institution of Mechanical Engineers, Part D: Journal of Automobile Engineering, 222(12): 2487-2496.

http://dx.doi.org/10.1243/09544070JAUTO932

\section{NOMENCLATURE}

SMD

$\Delta P$

$\dot{m}$

$L$

sauter mean diameter, $\mu \mathrm{m}$

atomizer pressure drop, $\mathrm{kg} / \mathrm{cm}^{2}$

mass flow of sprayed liquid, $\mathrm{kg} / \mathrm{s}$

spray length, $\mathrm{mm}$

\section{Greek symbols}

$\sigma$
$\mu$
$\rho$
$\alpha$

surface tension, $\mathrm{kg} / \mathrm{s}^{2}$

dynamic viscosity, $\mathrm{kg} / \mathrm{m} . \mathrm{s}$

liquid density, $\mathrm{kg} / \mathrm{m}^{3}$

spray angle, ${ }^{0}$

Subscripts

$L$

characteristic dimension

Abbreviations

BTDC before top dead center

SFC specific fuel consumption

AFR air fuel ratio

CPO crude palm oil

LHV lower heating value

BTE brake thermal efficiency

EGT exhaust gas temperature

CA crank angle

$\mathrm{HC}$ Hydrocarbon

SOC start of combustions

$\mathrm{CO}$ carbon monoxide

$\mathrm{CO}_{2} \quad$ carbon dioxide 